\section{Ensaio histórico-conceitual sobre a Atenção Primária à Saúde: desafios para a organização de serviços básicos e da Estratégia Saúde da Família em centros urbanos no Brasil}

\author{
A historical and conceptual model for Primary \\ Health Care: challenges for the organization of \\ primary care and the Family Health Strategy \\ in large Brazilian cities
}

\author{
${ }^{1}$ Departamento de Saúde \\ Pública, Universidade \\ de Santa Catarina \\ Florianópolis, Brasil. \\ Correspondência \\ E. M. Conill \\ Departamento de Saúde \\ Pública, Universidade \\ Federal de Santa Catarina. \\ Rua Vento Sul 306, \\ Florianópolis, SC \\ 88063-070, Brasil. \\ eleonorconill@yahoo.com.br
}

\begin{abstract}
This paper focuses on the experience with Primary Health Care as a strategy for reorganizing the health care model, based on reforms in this direction and their implementation in the Brazilian case. The article identifies a shift in the discourse concerning health sector reforms, with a return to emphasis on primary care and integration of services. The Brazilian context demands reflection on the possibilities for synergy between this strategy and other social policies and the factors needed to ensure adequate performance. Evaluation research has suggested that primary care activities are slightly superior as compared to traditional health care units, despite persistent difficulties in access, physical infrastructure, team formation, management, and organization of the network. These difficulties correlate with a low level of public financing, persistent segmentation of the system, and weak integration of primary care services with other levels of care. From the technical perspective, a reasonable target is to guarantee the strategy's continuity with the necessary adjustments, conditioned by the dynamics of the health care technical models involved in the dispute.
\end{abstract}

Primary Health Care; Health Services; Family Health

\section{Introdução}

Apesar da enorme influência da medicina hospitalar, a figura do clínico geral ou do médico de família talvez simbolize ainda hoje uma imagem idealizada da medicina. Esse tipo de prática foi se configurando com formas e importância distintas em diversos países sendo atualmente denominada de atenção primária, o que inclui, algumas vezes, o exercício de especialidades básicas ou a presença de outros profissionais. Duas concepções de Atenção Primária de Saúde são predominantes, a de cuidados ambulatoriais na porta de entrada ou a de uma política de reorganização do modelo assistencial, quer seja sob forma seletiva ou ampliada.

Optamos por enfocar a trajetória da atenção primária enquanto política de reforma setorial, reunindo observações de estudos que realizamos complementados com trabalhos mais recentes feitos para o caso brasileiro. Um dos desafios advém do fato de que nas práticas locais, objetos de nosso interesse, se entrelaçam determinantes das esferas macro e microssocial numa rede de fatores cuja complexidade nem sempre poderá ser desenvolvida dentro dos recortes e limites deste trabalho. Por isso, a importância de todas as contribuições que se fizerem necessárias, uma vez que a idéia é de que o panorama apresentado possa oferecer um conjunto de ponderações para facilitar a discussão do tema. 
A relação entre pobreza, doença e vida urbana está na origem dos modelos de assistência, proteção social e da prestação de serviços locais. A noção de distrito é encontrada nas propostas da "polícia médica" na Alemanha, nos comitês da Revolução Francesa e num conjunto diversificado de ações desenvolvidas por paróquias e municípios no contexto da Revolução Industrial Inglesa, incluindo a criação de dispensários que surgem como complemento à ação dos hospitais. Os centros de saúde norte-americanos do início do século XX visavam a integrar a prestação de serviços sociais e de saúde para comunidades excluídas, com o argumento de que a aplicação efetiva destes serviços requeria uma relação com a população em seu próprio terreno e mais próxima da moradia ${ }^{1}$. Muitos deles tinham em comum a responsabilidade sobre um distrito ou uma população definida e a coordenação dos recursos dentro desta área, atributos considerados essenciais nas conceituações atuais para caracterizar as práticas de atenção primária.

A difusão da noção de atenção primária é atribuída ao Relatório Dawson, elaborado pelo Ministro de Saúde do Reino Unido, que em 1920 a associou com a idéia de regionalização e hierarquização dos cuidados 2 . Conforme veremos a seguir, serão necessários mais de cinqüenta anos para que alguns destes princípios sejam postos em prática mesmo no Reino Unido.

Somente na década de sessenta, com a crise determinada pela expansão de serviços cada vez mais especializados é que ressurgirá nos Estados Unidos um movimento em favor da medicina ou saúde comunitária, com duas vertentes principais, de um lado os Departamentos de Medicina Social e Preventiva de centros universitários, e de outro, o contexto da "guerra à pobreza" desencadeada pelo Governo Federal. São suficientemente conhecidas as análises relacionando a emergência e difusão dessas propostas com a conjuntura de crise econômica e do modo de acumulação instalada nos países centrais a partir dos anos 70 e com o enfrentamento de uma situação explosiva determinada pelo crescimento de periferias urbanas, entre outros problemas 3,4 .

O conceito estabelecido como consenso mundial em 1978, destacou elementos que a Organização Mundial da Saúde (OMS) estava empenhada em difundir nesse momento: integração dos serviços locais num sistema nacional, participação, necessidade de ações intersetoriais e a relação da saúde com o desenvolvimento econômico e social. Esse discurso informará ao longo dessa década, de distintas maneiras e com distintos graus de intensidade, processos de reforma em países com modelos de prestação de serviços tão diversos quanto Cuba, Moçambique,
Canadá, Inglaterra, Espanha, para citar alguns exemplos.

Com base na revisão de diversas experiências, formulamos a hipótese que o conteúdo proposto se articulava em torno de dois pólos principais expressando respostas a necessidades de ordem econômica, política e social, mas também demandas oriundas dos movimentos sociais e setoriais desse contexto. De um lado, um pólo tecnocrático propondo a incorporação de medidas inovadoras e de racionalização das práticas (comunidade como fundamento das necessidades de saúde, hierarquização, coordenação e integração do cuidado), e de outro, um pólo participativo associado a uma maior democratização dos serviços (mudanças na divisão do saber com ampliação da equipe, incorporação de agentes da comunidade, acesso e controle social). O estudo das diversas conjunturas ou contextos de aplicação permitiria identificar seus elementos principais, combinações ou a direção predominante em torno de três eixos principais: racionalização, legitimação do Estado por meio de políticas públicas ou uma maior democratização dos serviços 5 .

Na primeira parte deste texto ilustramos, ainda que brevemente, a trajetória da atenção primária através da descrição dos casos das reformas na Província de Québec, Canadá, e do National Health Service (NHS) da Inglaterra. A diversidade de situações não permite a importação mecânica de qualquer elemento comparativo para o contexto brasileiro, mas a enorme importância dada à atenção primária nesses sistemas torna interessante sua análise pela coincidência com a estratégia atualmente adotada para reorganização das práticas no Sistema Único de Saúde (SUS). Isso também nos permitirá argumentar que, uma vez arrefecida a fase de um discurso centrado no controle de custos, na competição e na eficiência pode-se perceber os contornos de um novo movimento de reformas setoriais, no qual a ênfase na atenção primária e na integração dos serviços torna-se novamente importante.

Após situar elementos do contexto internacional, o tópico seguinte trata dessa trajetória no Brasil, começando pelos projetos experimentais na década de 70 e sua relação com o movimento de reforma sanitária cujos processos priorizaram as dimensões político-institucional e políticoadministrativa na primeira década de sua implantação até a emergência em 1994 do "Saúde da Família” com a mudança do status de programa para estratégia de reorientação do modelo assistencial.

De posse desse referencial, procedemos a uma síntese de pesquisas realizadas a partir da implantação dessa estratégia, principalmente 
aquelas que deram origem a relatórios oriundos de demandas do Ministério da Saúde ou foram decorrentes da atual política de institucionalização da avaliação implementada a partir de $2005^{6}$, organizando-as por blocos temáticos considerados centrais na análise dos sistemas de saúde. Se esta escolha introduz um viés de seleção, pretende contribuir, por outro lado, para o acompanhamento da incorporação dos resultados dessas avaliações no processo decisório, o que se constitui num dos principais objetivos dessa política cuja importância é destacada na conclusão.

\section{Reformas sanitárias e atenção primária de saúde: idas e vindas de um discurso}

Ao aderir em 1970/1971 aos princípios de cobertura universal estabelecidos pelo Governo Federal, Québec realizou uma reforma de caráter muito inovador. Na porta de entrada de uma rede de estabelecimentos hierarquizados por regiões foram criados os Centres Locaux des Services Communautaires (CLSC), cujo Conselho de Administração era majoritariamente constituído por usuários e cujo atendimento deveria privilegiar a integralidade da atenção ("la globalité des soins") e a dimensão familiar e comunitária dos cuidados. Esse período foi marcado por um importante crescimento de movimentos sociais urbanos com cooperativas de habitação e clínicas populares autônomas que influenciaram a criação desses centros. Os médicos generalistas estimulados pela perspectiva de ascensão de status pela grande ênfase na atenção primária, inicialmente aceitaram participar da experiência dos CLSC podendo optar pelo assalariamento ou pelo pagamento por ato. Embora esses centros tenham mostrado a viabilidade da prestação de um cuidado integral, foram gradativamente assumindo uma posição marginal na rede de serviços, sendo dirigidos para atendimento de imigrantes, programas de prestação de cuidado em domicílio para idosos ou serviços em regiões distantes 7 .

Na década de 1980 e início dos anos 1990, o discurso se modificou num contexto neoliberal de restrições orçamentárias e ajustes macroeconômicos com ações regulatórias que ultrapassaram o âmbito dessa província. Em Québec a descentralização foi adotada, com a criação de agências regionais encarregadas de realizar fusões de estabelecimentos, fechamentos de hospitais e a chamada "virada ambulatorial", na qual os CLSC voltaram a cena como estruturas de apoio 8 .

Em 2003, essas regionais transformaram-se em Agências de Desenvolvimento de Redes Locais de Serviços de Saúde e de Serviços Sociais com um papel de coordenação, incluindo o setor privado. Houve aumento na regulação do trabalho médico instituindo-se algumas atividades obrigatórias e um sistema de remuneração diferenciada para exercício em locais específicos. No centro dessas redes surgiu um novo estabelecimento denominado Centre de Santé et des Services Sociaux (CSSS), fruto das fusões dos CLSC e de hospitais de cuidados de curta e longa durações, com o objetivo de estabelecer corredores de serviços integrados. Na porta de entrada, foram criados os Groupes de Médècine de Famille (GMF), uma continuidade das policlínicas já existentes, agora com subvenção governamental para estrutura física e recursos humanos 9,10.

A análise das reformas realizadas em Québec mostra que a manutenção de direitos em saúde foi garantida durante uma conjuntura de controle de gastos por meio da redução seletiva da oferta com diminuição da atenção hospitalar em favor da reorganização de novos modos de prática. A atenção primária voltou à cena com uma "nova roupagem": menos intersetorial e participativa, uma estratégia para racionalizar a oferta, diminuir custos, facilitar o acesso e a coordenação dos cuidados. Vejamos agora como esses processos ocorreram nas reformas no caso da Inglaterra.

Em 1948, no momento da criação do NHS, fora preconizada a organização de um sistema descentralizado e pluralista sob controle municipal (as Local Authorities - LA). No entanto, em decorrência de negociações para superar a oposição médica a um controle local, o sistema foi estruturado de forma centralizada com três partes independentes: hospitais, serviços locais de saúde pública e serviços locais de assistência médica, odontológica, farmacêutica e de optometria. Os serviços comunitários, a saúde escolar e o saneamento continuaram sob controle das LA que permaneceram pouco integradas ao sistema 11 .

Os especialistas ("consultants") tornaram-se assalariados exercendo suas atividades em hospitais, e os generalistas ("General Practitionner" - GP), cuja prática tem raízes antigas nesse país, permaneceram em seus consultórios como prestadores liberais financiados pelo governo através de um sistema de pagamento por lista de pacientes sob sua responsabilidade. Embora com origens diferentes e associações profissionais distintas, os médicos têm na British Medical Association (BMA) uma interlocutora poderosa na representação de seus interesses junto ao governo.

Somente em 1974 ocorreu a primeira reforma importante criando-se autoridades regionais, de área e equipes de gestão distrital, mas o controle 
e o pagamento dos serviços de atenção primária permaneceram a cargo de uma estrutura separada. Em 1982, as autoridades de área foram suprimidas estimulando-se a descentralização e a gestão distrital por intermédio das District Health Authorities (DHA).

A introdução de uma concepção empresarial e a instituição de um mercado interno com ênfase na competição pública foram as principais mudanças adotadas pelas políticas de saúde do governo conservador que durou de 1983 a 1996. O princípio de regionalização foi rompido e as autoridades distritais passaram a realizar contratos com hospitais e outros serviços de atenção secundária, transformados em "trusts", ou seja, com a responsabilidade de gerar seu próprio orçamento. Os GPs foram também estimulados a administrar fundos para compra direta de serviços. Há controvérsia quanto aos resultados dessas medidas 12,13, mas o fato é que elas introduziram uma dinâmica favorável à atenção primária aumentando consideravelmente o status dos generalistas.

Esse aspecto será estrategicamente aproveitado na nova fase que se inicia com a chegada do partido trabalhista ao poder em 1997, com o compromisso de abolir o mercado interno substituindo a competição por um trabalho colaborativo entre as instituições que, no entanto, permaneceram como "trusts". A gestão local passou a ser responsabilidade de novas estruturas denominadas Primary Care Trusts (PCTs), às quais todos os GPs estão vinculados e onde, finalmente, começaram a trabalhar juntos as autoridades distritais e os órgãos de controle dos serviços de atenção primária.

Em funcionamento desde 2002, os PCTs parecem estar avançando na direção de uma maior integração entre os serviços, sendo a compra de cuidados especializados definida a partir das necessidades do nível local 14. Foram previstos investimentos para o período $2000 / 2010$ visando a reduzir os tempos de espera para no máximo 48 horas no caso dos GPs, três meses para especialistas e seis meses para cirurgias eletivas 15 . O monitoramento do acesso é hoje central nas atividades dos PCTs, cujo trabalho enfrenta o desafio de promover qualidade entre uma diversidade de prestadores liberais. Em janeiro de 2006, um novo documento apresentado ao Parlamento reiterava a continuidade dessas medidas 16 .

Tal como em Québec, a trajetória do sistema de saúde inglês mostra uma tendência de garantir e facilitar o acesso com a busca de maior integração entre os serviços, atribuindo destaque para o papel de coordenação de estruturas de atenção primária, ainda que com estratégias e arranjos institucionais bastante diversos.
A volta à cena da estratégia de Atenção Primária à Saúde é confirmada pelo Observatório Europeu de Sistemas e Políticas de Saúde, que analisou reformas orientadas pela Atenção Primária à Saúde em países da União Européia a partir de 1990 17. O papel crescente da atenção primária se deveria, em parte, à transferência de cuidados hospitalares para o nível ambulatorial havendo grande diversidade nas formas de organizar e de prestar estes serviços. As funções da Atenção Primária à Saúde adotadas pelo Observatório Europeu praticamente coincidem com os atributos sugeridos por Starfield 2 para avaliar estas práticas: primeiro contato, longitudinalidade, integralidade, coordenação, centralização na família, orientação para a comunidade, e que começaram a ser utilizados no Brasil com a validação de um instrumento desenvolvido na Johns Hopkins University, o Primary Care Assessment Tool (PCAT) 18 conforme veremos a seguir. Uma pesquisa desta autora com países da Organization for Economic Co-Operation and Development (OECD) mostrou que quanto maior a orientação do sistema para a atenção primária menor é o custo e melhor o desempenho na área materno-infantil. No entanto, para o conjunto de indicadores não havia diferenças importantes para os países agrupados no ranking superior ou intermediário de Atenção Primária à Saúde, com destaque para os seguintes atributos do sistema como um todo: distribuição eqüitativa de recursos, cobertura universal, baixa contrapartida financeira dos usuários e orientação integral e familiar nos serviços 19 .

Examinemos agora o contexto da emergência dessa política no Brasil para refletir acerca de seus limites e possibilidades a partir da síntese de alguns trabalhos já divulgados.

\section{Sobre as origens e implantação da Atenção Básica e a Estratégia Saúde da Família na reforma brasileira}

A partir da década de 1970, surgiram diversas iniciativas visando a ampliar as práticas nos centros de saúde tradicionalmente ligados à prestação de serviços de saúde pública para populações pobres, entre as quais podemos destacar: o projeto de saúde comunitária Murialdo da Secretaria Estadual de Saúde do Rio Grande do Sul, em Porto Alegre, com residência multiprofissional e que funcionou como pólo aglutinador para outros projetos semelhantes realizados em Vitória de Santo Antão, Rio de Janeiro, Teresina, São Luiz, Cotia, Sete Lagoas, Pelotas e Joinville, com a criação da Sociedade Brasileira de Medicina Geral Comunitária (SBMGC) 20,21; experiências de me- 
dicina comunitária como a de Montes Claros que serviram de base para programas de extensão de cobertura; o Programa de Interiorização das Ações de Saúde e Saneamento (PIASS) no Nordeste, que ao ser estendido para todo o país promoveu uma grande expansão da rede ambulatorial; além de experiências municipais em Lages, Campinas, Londrina e Niterói, por exemplo 22.

O desenho do SUS teve influência do ideário das reformas dos sistemas contemporâneos na década de setenta, mas os conhecimentos acumulados com novos modos de práticas e formação de recursos humanos em nível local não encontrarão eco no movimento sanitário, cujos esforços centraram-se em questões mais gerais das políticas e do direito à saúde.

Os primeiros anos da reforma foram marcados pela integração e fusões de instituições associadas à tentativa de manter e difundir novos princípios num contexto de grave crise fiscal e financeira. A partir de 1996, houve um impulso na política de descentralização com Normas Operacionais favorecendo um arcabouço legal e administrativo necessário ao novo papel atribuído para o poder local. Porém, mais do que reorganizar o modelo assistencial, o que predominou nesse momento foi o interesse em cumprir requisitos a fim de assegurar repasses federais, não sendo raros os exemplos em que a montagem das novas estruturas administrativas era coincidente com o momento em que o município assumia a gestão da rede de serviços 23 .

Surgiram propostas mostrando a necessidade de mudanças paradigmáticas com projetos estruturantes no campo da saúde e no campo dos serviços 24 , alertando-se para a importância da subjetividade dos usuários e dos coletivos de trabalho, com uma crítica contundente à racionalidade tecnoburocrática 25,26.

A confluência de um conjunto de fatores parece explicar a emergência do Programa Saúde da Família (PSF) nesse momento: a experiência bem sucedida das ações do Programa de Agentes Comunitários de Saúde (PACS) no Nordeste, o vazio programático para a questão assistencial no SUS e os atrativos políticos que um programa desta ordem poderia representar mesmo para um governo de cunho neoliberal. É possível também que oferecer um incentivo financeiro para contratação de equipes se configurasse como uma medida operacionalmente viável para estimular o reordenamento da atenção básica.

Se no primeiro documento ministerial elaborado em 199427 o PSF é entendido como um programa, no referencial que se segue passa a ser considerado uma estratégia para reorientação do modelo assistencial com caráter substitutivo das práticas convencionais 28 .
Para Vianna \& Dal Poz 29, teria havido uma interação positiva entre a sua implantação e a descentralização, com o PSF facilitando a adoção do financiamento per capita das ações básicas. O que estaria impedindo sua expansão seriam as estruturas burocráticas ainda pesadas, o corporativismo, o aparelho formador e os preconceitos em relação à tecnologia simplificada. É importante lembrar que o Banco Mundial havia divulgado seu relatório anual propondo pacotes mínimos de serviços 30 exacerbando críticas a formas de Atenção Primária à Saúde que pudessem significar um retrocesso de direitos.

Analisamos a implantação do PSF por meio do estudo do caso de Florianópolis no período 1994/2000 utilizando uma combinação de metodologias de avaliação ${ }^{31}$. O atraso da capital catarinense confirmava resistências de ordem político-ideológica com prioridade para oficinas de territorialização, numa conjuntura em que o PSF ainda não era considerado uma estratégia de reforma sem garantias de sua continuidade. Com a troca do poder municipal inicia-se uma política expansionista havendo concordância em nível de gestão de que obter recursos humanos adequados se constituía num dos problemas centrais.

Para as coordenações dos postos o PSF havia gerado avanços na prevenção, na consciência sanitária e na realização de visitas domiciliares, citando-se o agente comunitário de saúde como um grande fator de mudança neste sentido. No entanto, era unânime a percepção de que esses avanços ficavam prejudicados pelo dimensionamento inadequado entre equipe e população. As dificuldades quanto ao acesso coincidiam com a percepção das famílias, para as quais a principal diferença também se devia à presença do agente comunitário. Na grade avaliativa final, o grau de implantação do programa foi considerado moderadamente adequado com problemas no acesso (relação inadequada entre equipe e o número de famílias) e numa das dimensões da integralidade (referência). Concluímos que essa dificuldade no acesso poderia dificultar as vantagens obtidas nos demais itens da integralidade ao prejudicar a realização de atividades de promoção, prevenção e visitas devido à sobrecarga das equipes. Havendo problemas na referência para especialidades, o cuidado mais complexo tornava-se também difícil e a integralidade ficava prejudicada como um todo.

Alguns aspectos sugeridos por este trabalho vêm a se confirmar nos estudos do período que se segue, o qual será marcado por ações do Projeto de Expansão e Consolidação do Saúde da Família (PROESF), apoiado pelo Banco Mundial e estruturado em três componentes principais: 
expansão da estratégia em municípios de grande porte, desenvolvimento de recursos humanos, monitoramento e avaliação 32 .

Em 2004, as Regiões Nordeste, Centro-Oeste e Sul apresentavam as maiores proporções de população coberta pelo PSF, aproximadamente $55 \%, 41 \%$ e $38 \%$, seguidas das Regiões Norte e Sudeste, com 34\% e 30\%. De 1998 a 2004, houve expansão importante em todas as regiões, mas com cobertura maior nos municípios com Índice de Desenvolvimento Humano (IDH) baixo. Embora tenha havido adesão precoce de cidades periféricas às regiões metropolitanas, a partir de 2000 a ampliação ocorreu em municípios menores, fato que começa a se modificar recentemente 33,34.

Existem poucos trabalhos avaliando a estrutura física das unidades, o mesmo ocorrendo em relação aos custos e ao financiamento. Num estudo comparativo Nordeste/Sul, os trabalhadores referiram baixa satisfação com essa estrutura em ambas as regiões e modelos de atenção, sendo que a principal diferença entre as equipes do PSF e as tradicionais foi decorrente da presença dos agentes comunitários 35 . A maioria dos médicos e enfermeiros mostrava-se otimista em relação ao programa citando o ambiente na equipe como um aspecto positivo, mas consideravam sua atividade desgastante e eram freqüentes os vínculos precários, pouca experiência ou formação na área 35,36 . Os gestores aprovavam o programa e a equipe propostos pelo Ministério da Saúde, porém sugeriam a inclusão de dentista e de assistente social citando dificuldades para encontrar "médicos generalistas" 37.

Uma pesquisa em municípios paulistas mostrou uma correlação entre a eficácia da gestão e a efetividade do sistema municipal, havendo necessidade de ganhos substanciais neste sentido. Municípios de grande porte tendem a ter maior capacidade e maior aprendizado institucional, mas muitos ainda mostravam pouca experiência e maturidade no PSF. Quanto mais baixa a governabilidade com a existência de conflitos entre os agentes (Conselho, Câmara, prestadores, Secretaria Estadual, Ministério da Saúde, Ministério Público) piores eram os resultados 34 .

No que diz respeito ao desempenho, o programa tende a favorecer um trabalho territorializado, com participação em atividades na comunidade e bons resultados na cobertura de ações programáticas 35,38 . No entanto, em algumas cidades estudadas no Estado do Rio de Janeiro notou-se que a ação setorial focalizada não parecia modificar a "lei do cuidado inverso": quanto pior a condição econômica do município pior a cobertura e a qualidade do atendimento 38 .

A avaliação dos atributos da atenção primária a partir da aplicação do PCAT tem mostrado resultados variáveis. Tanto no interior como na capital de São Paulo, as dimensões com as quais os usuários estavam mais satisfeitos eram a porta de entrada, o vínculo e os profissionais 39,40 . Na capital a acessibilidade foi referida por usuários, profissionais e gestores como a pior dimensão em todos os estratos de exclusão tanto no PSF como nas unidades básicas de saúde tradicionais. Nesse caso, o índice de atenção básica (IAB) foi comparativamente mais favorável ao PSF em todos os estratos, mas quanto maior a exclusão pior era a avaliação.

O impacto do PSF nos indicadores de saúde permanece controverso. A análise de alguns indicadores selecionados para o Brasil de 1998 a 2003/2004 aponta para a diminuição da brecha entre as faixas de IDH sugerindo efeitos positivos para a eqüidade ${ }^{33}$, porém um estudo feito em municípios nordestinos de grande porte não identificou diferenças significativas nos indicadores de saúde da criança entre áreas cobertas e não cobertas pelo PSF. Nesse caso, havia uma clara relação desses indicadores com a situação sócio-econômica, confirmando-se assim, a já conhecida importância da determinação social desses agravos 41 .

As análises acerca do PSF em grandes centros mostram obstáculos decorrentes do padrão de desenvolvimento urbano e do acentuado processo de favelização, com a necessidade de ações inter-setoriais sinérgicas face às situações de extrema precariedade. A essas situações se somariam problemas setoriais pela existência de sistemas municipais com baixos graus de eficácia e sustentabilidade na gestão e problemas de financiamento decorrentes da política de repasses, com a violência urbana repercutindo no cotidiano e na rotatividade das equipes 34 .

Para finalizar, gostaríamos de destacar algumas das recomendações da avaliação feita em dez centros urbanos em 2001/2002, sob encomenda do Ministério da Saúde 42: necessidade de estratégias de negociação com as corporações médicas e de enfermagem; integração de equipes nos serviços existentes ou no interior de uma unidade básica de saúde para compartilhamento de recursos e interconsultas; redução do número de famílias adscritas em função do grande leque de atividades; práticas para atrair usuários com adscrição próxima ao local do trabalho, horários noturnos, melhor acolhimento e, adequação do financiamento à situação peculiar das periferias urbanas com incentivos salariais para áreas de risco social e epidemiológico. Além disso, chamam atenção para o fato de que um sistema integrado de serviços necessita de investimentos nos demais níveis de complexidade e não apenas na atenção básica. 
Em março de 2006 foi aprovada a Política Nacional de Atenção Básica com uma revisão da legislação em função da experiência acumulada e das diretrizes do novo pacto entre as esferas de governo 43. O Pacto de Gestão regulamentou o bloco financeiro da atenção básica para superar a fragmentação vigente, extinguindo-se a vinculação de incentivos por faixas de cobertura o que prejudicava os grandes centros. O Pacto pela Vida reiterou como prioridade a consolidação e a qualificação da Estratégia Saúde da Família como modelo de atenção básica e centro ordenador das redes de atenção à saúde 44 .

\section{Nem cavalo de Tróia nem travessia messiânica para o SUS: considerações finais acerca da Estratégia Saúde da Família enquanto política de reforma da atenção básica}

Conforme mostramos na introdução deste trabalho, a prestação de serviços locais como forma de lidar com a pobreza e a exclusão social é antiga. A história da proposta de organizar serviços orientados pela atenção primária é marcada por uma trajetória de sucessivas reconstruções até se consolidar como uma política de reforma, uma alternativa diante da permanente crise dos sistemas de saúde contemporâneos. Esse discurso difunde-se com grande intensidade nas décadas de 1960 e 1970 associado a princípios participativos e de democratização das práticas, retrocede na fase de reformas neoliberais dos anos 1980 para reaparecer a partir da última década do século $\mathrm{XX}$, com uma roupagem mais racionalizadora e instrumental. Seria interessante aprofundar os fatores conjunturais que poderiam explicar as diferenças desses momentos, principalmente entender o atual interesse que o Banco Mundial demonstra ao apoiar a implementação dessa política no contexto brasileiro.

Também aqui essas propostas surgiram ligadas a projetos docente-assistenciais de reforma da educação médica ou de programas localizados de saúde comunitária, mas não encontraram eco na primeira década de funcionamento do SUS. A emergência do PSF parece estar relacionada com a precariedade de respostas dadas no plano assistencial pela reforma, mas a envergadura e a continuidade de sua implementação fazem com que esse programa venha a se constituir num caso particular de aplicação de uma política de atenção primária num país de inserção periférica na economia mundial.

Há na extensão e difusão dessa política (e apenas nisso) alguma semelhança com o que aconteceu nos primeiros anos da reforma de
Québec. Uma das razões que nos levaram a descrever os processos realizados nessa província e no NHS da Inglaterra foi o de ilustrar o percurso da Atenção Primária à Saúde enquanto política de reorientação do modelo assistencial em dois países centrais, cuja organização dos serviços de saúde tem adquirido uma importância paradigmática. Mas também queríamos destacar a importância de se ter em mente que a dinâmica dos atores sociais, especialmente daqueles que são sujeitos das relações no cotidiano assistencial, reconstrói e reconfigura teorias, normas e prescrições tecno-burocráticas.

Esses casos apontam também para a necessidade de tolerância quanto ao tempo necessário para construção de novos modos de práticas no sistema de saúde, o qual precisa levar em conta, portanto, o papel e a expressão dos diversos grupos sociais envolvidos. Assim, a intenção de que os CLSC fossem a porta de entrada em Québec não encontrou adesão efetiva dos médicos, porém, trinta anos depois, os GMF parecem ser uma variante mais restrita porém consensual desta idéia. Surpreendentemente, os CLSCs passam a se localizar em hospitais para promover a integração do cuidado, facilitando formas de trabalho que foram sendo amadurecidas pelas práticas profissionais no cuidado de pacientes crônicos. Na Inglaterra, uma oposição à lógica do mercado interno favoreceu o desenvolvimento de um novo modelo baseado na integração e na cooperação, o qual no entanto, manteve e se beneficiou de algumas das medidas que haviam sido anteriormente implantadas, como a autonomia orçamentária das instituições. Apesar da inegável turbulência dos últimos decênios, há nesses sistemas forte tradição de consulta aos envolvidos, de prestação de contas à sociedade e de continuidade na manutenção dos grandes princípios acordados.

Sem dúvida, ocorreram importantes avanços nesse sentido em nosso meio, com a existência dos Conselhos e de um planejamento que tende a ser mais comunicativo por meio do estabelecimento de metas pactuadas. Mas é preciso cautela com um agir tecnocrático e com o desequilíbrio dele resultante: uma formidável engenharia administrativa mas uma ausência relativa de alguns atores sociais importantes como as corporações profissionais. Um aspecto que tem sido posto em relevância para a qualidade dos sistemas contemporâneos é a chamada "responsiveness" 45, ou seja, a capacidade de ser permeável às demandas dos que os utilizam e, acrescentaríamos, daqueles que neles trabalham. É verdade que gradativamente algumas demandas foram incorporadas ao PSF, tais como a ampliação da equipe com a presença de dentistas e o modo de financiamen- 
to, de forma a não prejudicar municípios de grande porte.

Um aspecto crucial da discussão das possibilidades dessa política diz respeito aos limites impostos pela heterogeneidade estrutural da formação social brasileira e suas conseqüências no desenvolvimento econômico e social do país e nas condições de vida da população. Os trabalhos que apresentamos mostram que o impacto do PSF nos indicadores de saúde permanece controverso, fato que não se constitui numa surpresa, uma vez que existe farta bibliografia sobre o papel limitado dos serviços na determinação social da doença.

A questão que nos parece central é refletirmos se o PSF tem potencial para somar-se de forma sinérgica a outras políticas públicas no enfrentamento dessa situação e, neste caso, quais os fatores setoriais que se mostram necessários para garantir um desempenho adequado.

As evidências atuais apontam para uma discreta superioridade do programa em relação às atividades de unidades tradicionais com a incorporação de práticas de territorialização, maior vínculo, envolvimento comunitário e acompanhamento de prioridades programáticas, o que é coerente com o cumprimento de seu referencial normativo. No entanto, o acesso permanece como um grande nó crítico, com dificuldades na estrutura física e nas equipes, fragilidades da gestão e na organização da rede de serviços. Já demonstramos o quanto os problemas no acesso podem vir a comprometer avanços no plano da integralidade.

Três categorias sugeridas por Mendes 46 para a análise dos sistemas de serviços nos parecem importantes de forma a correlacionar essas dificuldades com outras mais gerais que se situam no âmbito da macrorregulação, as quais precisarão ser melhor discutidas e enfrentadas pela sociedade brasileira: o baixo patamar do financiamento público atualmente vigente, a persistência de segmentação do sistema e a ausência de integração dos serviços de atenção básica e, em especial, aqueles do PSF, ao sistema como um todo. Também não é possível desconhecermos a necessidade de importantes mudanças culturais e no aparelho formador para que uma prática que não tem tradição nem nas corporações profissionais nem diante da população venha a legitimar-se.

Sem minimizar a importância da continuidade de estudos de avaliação, temos insistido acerca de dois desafios a serem superados nesse sentido: o desafio da profusão (de estruturas, de formulários, de relatórios, de dados, de pesquisas) e o desafio de comunicação (da divulgação, do retorno das informações, da implementação de mudanças). Ocorre assim um estranho paradoxo: uma demanda excessiva de informações (muitas vezes sobrecarregando equipes locais) com dificuldades na realização de mudanças.

Os eixos de racionalização dos serviços, de legitimação política do Estado através das políticas públicas ou de democratização das práticas, permeiam as ações da estratégia da saúde da família, atual política brasileira para a reforma da atenção básica, porque os conceitos que compõem esta política representam a resposta a um conjunto de contradições do sistema de serviços e do contexto social. Mas o PSF nem se constitui numa espécie de cavalo de Tróia nem tampouco representa a garantia de uma travessia messiânica para os problemas do SUS. Muitos e importantes aspectos já são suficientemente visíveis com o acompanhamento e os estudos de sua implementação para que se realizem ajustes necessários. Garantir sua continuidade realizando esses ajustes com respeito à diversidade de práticas e de situações parece ser um horizonte razoável a ser defendido, do ponto de vista técnico. Sabemos, no entanto, que é a dinâmica de atores nas disputas de projetos tecnoassistenciais que delineiam horizontes na arena setorial, uma entre tantas outras que se estabelece na complexidade da produção social. 


\section{Resumo}

O trabalho enfoca a trajetória da Atenção Primária à Saúde enquanto política de reorganização do modelo assistencial, tendo como referência reformas orientadas por este princípio e sua implantação no caso brasileiro. Aponta-se para uma mudança no discurso das reformas setoriais com um retorno da ênfase na Atenção Primária à Saúde e na integração dos serviços. No contexto brasileiro, é necessário refletir sobre as possibilidades de sinergia dessa estratégia com outras políticas sociais e sobre os fatores necessários para garantir seu desempenho. Os estudos de avaliação mostram uma discreta superioridade de suas atividades sobre aquelas de unidades tradicionais, mas permanecem dificuldades no acesso, na estrutura física, na

\section{Referências}

1. Rosen G. Da polícia médica à medicina social. Rio de Janeiro: Edições Graal; 1980.

2. Starfield B. Atenção primária. Equilíbrio entre necessidades de saúde, serviços e tecnologia. Brasília: Organização das Nações Unidas para a Educação, a Ciência e a Cultura/Ministério da Saúde; 2004.

3. Donnangelo FMC, Pereira L. Saúde e sociedade. São Paulo: Livraria Duas Cidades; 1976.

4. Breilh J. Community medicine under imperialism: a new medical policy? Int J Health Serv 1979; 9: 5-24.

5. Conill EM, O'Neill M. La notion de santé communautaire: éléments de comparaison internationale. Can J Public Health 1984; 75:166-75.

6. Ministério da Saúde. Avaliação da atenção básica em saúde: caminhos da institucionalização da avaliação. Brasília: Ministério da Saúde; 2005.

7. Conill EM. Les implications de la santé communautaire en tant que nouvelle politique de santé. Analyse du cas du Québec [Tese de Doutorado]. Paris: Institut du Développement Economique et Social, Université Paris 1/Sorbonne; 1982.

8. Conill EM. A recente reforma dos serviços de saúde na província do Québec, Canadá: as fronteiras da preservação de um sistema público. Cad Saúde Pública 2000; 16:963-71.

9. Canada. Project de Loi 25, chapitre 21. Loi sur les Agences de Développement de Réseaux Locaux de Services de Santé et de Services Sociaux, Assemblée Nationale. Québec: Editeur Officiel du Québec; 2003.

10. Ministère de la Santé et des Services Sociaux. Topics service organisation. Family medecine groups http:/ /www.gouv.qc.ca (acessado em 28/Jul/2004). formação das equipes, na gestão e na organização da rede. Essas dificuldades se correlacionam com o baixo patamar de financiamento público, a persistência de segmentação no sistema e a fraca integração dos serviços de atenção básica com outros níveis de atenção. Garantir a continuidade dessa estratégia realizando os ajustes necessários é um horizonte razoável a ser defendido do ponto de vista técnico, o qual será sempre condicionado pela dinâmica dos projetos tecnoassistenciais em disputa.

Atenção Primária à Saúde; Serviços de Saúde; Saúde da Família

11. Doyal L. The National Health Service in Britain. In Doyal L, editor. The political economy of health. London: Pluto Press; 1979. p. 177-214.

12. Maynard A, Bloor K. Introducing a market to the United Kingdom's National Health Service. N Engl J Med 1996; 334:604-8.

13. Dean M. Five candles on NHS-reforms' birthday cake. Lancet 1996; 347:1035.

14. Conill EM, Giovanella L. O acesso e a integralidade na atual reforma do National Health Service (NHS) da Inglaterra: da competição à integração. In: 11o Congresso Mundial de Saúde Pública/8 Congresso Brasileiro de Saúde Coletiva. Rio de Janeiro: ABRASCO. p. 50.

15. Department of Health. The NHS plan. A plan for investment, a plan for reform. London: Department of Health; 2000 .

16. Department of Health. Our health, our care, our say: a new direction for community services. http:// www.dh.gov.uk (acessado em 06/Mar/2006).

17. Saltmann RB, Rico A, Boerma W, editors. Primary care in the driver's seat? Organizational reform in European primary care. European Observatory on Health Sistems and Policies Series. Berkshire: Open University Press; 2006.

18. Almeida C, Macinko J. Validação de uma metodologia de avaliação rápida das características organizacionais e do desempenho dos serviços de atenção básica do Sistema Único de Saúde (SUS) em nível local. Brasília: Organização Pan-Americana da Saúde; 2006.

19. Starfield B, Shi L. Policy relevant determinants of health: an international perspective. Health Policy 2002; 60:201-18. 
20. Busnello ED. O projeto do sistema de saúde comunitária. Porto Alegre: Secretaria da Saúde do Rio Grande do Sul; 1975.

21. Falk JW. A medicina de família e comunidade e sua entidade nacional: histórico e perspectivas. Revista Brasileira de Medicina de Família e Comunidade 2004; 1:5-10.

22. Mendes EV, organizador. Distrito sanitário: o processo social de mudança das práticas sanitárias do Sistema Único de Saúde. São Paulo: Editora Hucitec/Rio de Janeiro: ABRASCO; 1993.

23. Bodstein R. Atenção básica na agenda da saúde. Ciênc Saúde Coletiva 2002; 7:401-12.

24. Mendes EV. Uma agenda para a saúde. São Paulo: Editora Hucitec; 1996.

25. Campos GWS. Saúde pública e a defesa da vida. São Paulo: Editora Hucitec; 1991.

26. Campos GWS. Reforma da reforma, repensando a saúde. São Paulo: Editora Hucitec; 1992.

27. Fundação Nacional de Saúde. Programa Saúde da Família - saúde dentro de casa. Brasília: Ministério da Saúde; 1994.

28. Ministério da Saúde. Saúde da família: uma estratégia para a reorientação do modelo assistencial. Brasília: Ministério da Saúde; 1998.

29. Vianna ALD, Dal Poz MR. A reforma sanitária do sistema de saúde no Brasil e Programa Saúde da Família. Physis (Rio J) 1998; 8:12-48.

30. Banco Mundial. Relatório sobre o desenvolvimento mundial 1993: investindo em saúde. Washington DC: Banco Mundial; 1993.

31. Conill EM. Políticas de atenção primária e reformas sanitárias: discutindo a avaliação a partir da análise do Programa Saúde da Família em Florianópolis, Santa Catarina, Brasil, 1994-2000. Cad Saúde Pública 2002; 18 Suppl:S191-202.

32. Departamento de Atenção Básica, Ministério da Saúde. PROESF. Expansão e Consolidação Saúde da Família. http://dtr2002.saude.gov.br/proesf/ Site/Paginas/Componetes.htm (acessado em 09/ Dez/2006).

33. Departamento de Atenção Básica, Ministério da Saúde. Saúde da família no Brasil. Uma análise de indicadores selecionados, 1998-2004. Brasília: Ministério da Saúde; 2006.

34. Vianna ALD, Rocha JSY, Elias PE, Ibañez N, Novaes MHD. Modelos de atenção básica nos grandes municípios paulistas. Ciênc Saúde Coletiva 2006; 11:577-606

35. Fachini LA, Piccini RX, Tomasi E, Thumé E, Silveira DS, Siqueira FV, et al. Desempenho do PSF no Sul e no Nordeste do Brasil: avaliação institucional e epidemiológica da atenção básica. Ciênc Saúde Coletiva 2006; 11:669-81.
36. Machado MH, coordenador. Perfil dos médicos e enfermeiros do Programa de Saúde da Família no Brasil. Brasília: Departamento de Atenção Básica, Ministério da Saúde; 1999.

37. Machado $\mathrm{MH}$, coordenador. Pesquisa de opinião dos gestores sobre o Programa de Saúde da Família no Brasil. Brasília: Departamento de Atenção Básica, Ministério da Saúde; 2000.

38. Szwarcwald CL, Mendonça MHM. Indicadores de atenção básica em quatro municípios do Estado do Rio de Janeiro, 2005: resultados de inquérito domiciliar de base populacional. Ciênc Saúde Coletiva 2006; 11:643-55.

39. Ibañez N, Rocha JSY, Castro PC, Ribeiro MCSA Forster AC, Novaes MHD, et al. Avaliação do desempenho da atenção básica no Estado de São Paulo. Ciênc Saúde Coletiva 2006; 11:683-703.

40. Elias PE, Ferreira CW, Alves MCG, Cohn A, Kishima V, Escrivão Júnior A, et al. Atenção básica em Saúde: comparação entre PSF e UBS por extrato de exclusão social no Município de São Paulo. Ciênc Saúde Coletiva 2006; 11:633-41.

41. Roncalli AG, Lima KC. Impacto do Programa Saúde da Família sobre indicadores de saúde da criança em municípios de grande porte da região Nordeste do Brasil. Ciênc Saúde Coletiva 2006; 11:713-24.

42. Escorel S, coordenador. Avaliação da implementação do Programa Saúde da Família em dez grandes centros. Síntese dos principais resultados. Brasília: Departamento de Atenção Básica, Ministério da Saúde; 2002.

43. Ministério da Saúde. Portaria no. 648 de 28 de março de 2006. Aprova a Política Nacional de Atenção Básica estabelecendo a revisão das diretrizes e normas para a organização da Atenção básica para o Programa Saúde da Família (PSF) e Programa Agentes Comunitários de Saúde (PACS). Diário Oficial da União 2006; 29 mar.

44. Ministério da Saúde. Pacto pela saúde. http:// portal.saude.gov.br/portal/saude/area.cfm?id_ area $=1021$ (acessado em 11/Dez/2006).

45. Figueras J, McKee M, Mossialos E, Saltman RB. Series editors' introduction. In: Saltmann RB, Rico A, Boerma W, editors. Primary care in the driver's seat? Organizational reform in European primary care. European Observatory on Health Systems and Policies Series. Berkshire: Open University Press; 2006. p. xv-xvi.

46. Mendes EV. Os grandes dilemas do SUS. Tomo I. Salvador: Casa da Qualidade Editora; 2001.

Recebido em 01/Jun/2007

Aprovado em 04/Jun/2007 